\title{
Gaya Bahasa dalam Acar Indonesia Lawyers Club (ILC) Di Tv One Edisi Januari - Februari 2019
}

\author{
Nama Penulis ${ }^{1 *}$, Nama Penulis ${ }^{2}$, dan Nama Penulis ${ }^{3}$ \\ Muhammad Subhan, Hetilaniar, Zainal Abidin
}

\author{
Program Studi Pendidikan Bahasa dan Sastra Indonesia, Universitas PGRI Palembang \\ Mssubhan97@gmail.com \\ Hetilaniar@univpgri-palembang.ac.id \\ Zainalabidin@univpgri-palembang.ac.id
}

\begin{abstract}
Abstrak
Masalah dalam penelitian ini adalah ada berapakah gaya bahasa yang digunakan dalam acara talkshow indonesia Lawyers Club (ILC) di TV One edisi Januari-Februari 2019. Penelitian ini mendeskripsikan untuk mengetahui gaya bahasa yang digunakan narasumber dalam acara Talkshow Indonesia Lawyers Club (ILC) di Tv One edisi Januari-Februari 2019. Metode penelitian yang digunakan dalam penelitian ini adalah metode kualitatif deskriptif. Pengumpulan data menggunakan teknik rekam dan catat. Hasil penelitian ini menunjukan bahwa Terdapat empat gaya bahasa yang digunakan dalam acara Talkshow Indonesia Lawyers Club edisi Januari-Februari 2019 yaitu, (1) Gaya bahasa penegasan : apofasis, repetisi, aliterasi, pleonasme, retoris, klimaks, antiklimaks, koreksio, dan preterio. (2) Gaya bahasa sindiran : Sarkasme dan sinisme. (3) Gaya bahasa pertentangan : antitesis, oksimoron. (4) Gaya bahasa perbandingan : sinestesia, alegori, antonomasia, hiperbola. Gaya bahasa yanag dominan muncul dari ketiga tema dalam penelitian ini ialah gayabahasa repitisi yang termasuk kedalam gaya bahasa penegasan. Gaya bahasa repetisi tersebut berjumlah 23 kalimat.
\end{abstract}

Kata Kunci: Gaya Bahasa, Acara Talkshow Indonesia Lawyers Club (ILC)

\section{PENDAHULUAN}

Sebagai alat komunikasi tentu televisi mempunyai fungsi bagi penggunanya, yaitu sebagai sarana hiburan, dan sebagai media pendidikan. Ada beberapa acara talkshow yang disuguhkan di televisi, salah satunya ialah acara talkshow Indonesia Lawyers Club (ILC) yang merupakan salah satu program televisi yang ada di TV One. Indonesia Lawyers Club (ILC) merupakan acara talkshow yang menampilkan dialog mengenai masalah hukum, politik dan kriminalitas yang dipandu oleh Karni llyas sebagai moderatornya. Acara ini dikemas dalam suasana santai, menarik, dan humoris. Dalam acara tersebut biasanya menampilkan dialog mengenai masalah hukum, politik, dan kriminalitas selama 210 menit. Acara tersebut manampilkan beberapa narasumber yang dapat dijadikan sumber informasi yang kemudian di bahas melalui forum diskusi.

Indonesia Lawyers Club (ILC) merupakan acara talkshow yang edukatif dan inspiratif. Bahasa yang digunakan dalam acara tersebut juga sangat lugas, tegas, spontanitas, dan tanpa basabasi sehingga membuat acara ini berbeda dengan acara lainnya. Selain itu moderator dan narasumber pada acara Indonesia Lawyers Club menggunakan bahasa yang mengkritik kesenjangan yang terjadi Pada pemerintah, politik, maupun masalah yang ada di negeri ini. Oleh karena itu peneliti memilih Indonesia Lawyers Club (ILC) sebagai objek yang menarik untuk diteliti. Gaya bahasa yang digunakan dalam acara tersebut pun tidak membosankan dan monoton untuk didengarkan oleh pemirsa. Moderator dan narasumber selalu menggunakan gaya bahasa yang menimbulkan kesan mendalam bagi pendengar maupun penonton acara talkshow Indonesia Lawyers Club (ILC). Hal ini membuat narasumber ketika berbicara sering menggunakan kata kiasan ataupun sindiran agar tidak terjadi selisih paham dengan narasumber lainnya. 
Menurut Tarigan (2009:4) gaya bahasa adalah bentuk retorik, yaitu penggunaan kata-kata dalam berbicara dan menulis untuk meyakinkan atau mempengaruhi penyimak dan pembaca. Gaya bahasa juga terdapat dalam setiap ragam bahasa: ragam tulis dan ragam lisan, ragam nonsatra dan ragam sastra, karena gaya bahasa dalam konteks tertentu oleh orang tertentu untuk maksud tertentu. Gaya bahasa merupakan pemanfaatan kekayaan bahasa yang membuat sebuah karya sastra semakin hidup dalam menyampaikan pikiran dan perasaanya baik dalam bentuk lisan maupun tulisan. Gaya bahasa adalah metode terdekat yang dapat digunakan oleh pemirsa untuk memaknai sebuah berita di televisi, karena gaya bahasa merupakan salah satu sarana penutur untuk mengatakan sesuatu dengan cara pengiasan bahasa secara tidak langsung mengungkapkan makna. Setiap manusia di bumi ini memiliki gaya bahasa yang berbeda-beda satu sama lainnya. Itulah sebabnya gaya bahasa seseorang menjadi ciri khas pribadi. Pembicaraan mengenai gaya bahasa sangatlah luas, menurut Waridah (2009:322) secara garis besar, gaya bahasa terdiri atas empat jenis yaitu, (1) gaya bahasa penegasan, yaitu kata-kata berkias yang menyatakan penegasan untuk meningkatkan kesan pengaruhnya terhadap pendengar ataupun pembaca, (2) gaya bahasa sindiran, yaitu jenis gaya bahasa yang menggunakan kata kiasan untuk mengungkapkan sebuah sindiran atau suatu yang sebaliknya, (3) gaya bahasa perbandingan, adalah gaya bahasa yang menggunakan kata-kata kiasan dalam bentuk perbandingan untuk meningkatkan kesan terhadap pembaca atau pendengarnya, dan (4) gaya bahasa pertentangan, adalah kata-kata berkias yang menyatakan pertentangan dengan yang dimaksudkan sebenarnya oleh pembicara atau penulis dengan maksud untuk memperhebat atau meningkatkan kesan dan pengaruhnya terhadap pembaca atau pendengarnya.

Berdasarkan uraian di atas peniliti tertarik melakukan penelitian tentang gaya bahasa dalam acara talkshow Indonesia Lawyers Club (ILC) di TV One edisi Januari-Februari 2019 dengan alasan karena gaya bahasa dalam acara tersebut memiliki efek persuasif untuk menarik perhatian penonton untuk menonton acara tersebut. Adanya gaya bahasa membuat sebuah kalimat akan menjadi lebih hidup dan menimbulkan tanggapan pemikiran pendengarnya. Selain itu hal lain yang menarik ialah ketika menemukan makna dan fungsi dalam gaya bahasa seseorang dapat menemukan hal-hal yang memberikan kesan lain tidak monoton, sehingga bahasa menjadi indah, menarik dan menjadikan sebuah berita acara menjadi lebih hidup. Adapun subfokus penelitian ini adalah penggunaan gaya bahasa dalam acara talkshow Indonesia Lawyers Club (ILC) di TV One edisi Januari - Februari 2019 dan tujuan penelitian ini untuk mengetahui gaya bahasa yang digunakan narasumber dalam acara talkshow Indonesia Lawyers Club (ILC) di Tv One edisi Januari-Februari 2019.

\section{METODE/EKSPERIMEN}

Menurut Tarigan (2009:4) gaya bahasa merupakan bentuk retorik, yaitu penggunaan kata-kata dalam berbicara dan menulis untuk meyakinkan atau mempengaruhi penyimak dan pembaca. Kata retorik berasal dari bahasa Yunani rhetor yang berarti orator atau ahli pidato. Pada masa Yunani kuno retorik memang merupakan bagian penting dari suatu pendidikan dan oleh karena itu, berbagai macam gaya bahasa sangat penting dan harus dikuasi benar-benar oleh orang-orang Yunani dan Romawi yang telah memberi nama terhadap berbagai macam seni persuasi ini.

Wiyanto (2012:286) mengatakan bahwa gaya bahasa adalah kalimat-kalimat yang disusun secara khusus untuk membangkitkan perasaan pembaca. Sastrawan perlu menyusun kalimat secara khusus, dengan kata lain sastrawan perlu "menggayakan" kalimat, agar pembaca tersentuh perasaannya.

Gaya atau khususnya gaya bahasa dikenal dalam retorika dengan istilah style. kata style diturunkan dari kata Latin stilus, yaitu semacam alat untuk menulis pada lempengan lilin. Keahlian menggunakan alat ini akan mempengaruhi jelas tidaknya tulisan pada lempengan tadi. Kelak pada waktu penekanan dititik beratkan pada keahlian untuk menulis indah, maka style lalu berubah menjadi kemampuan dan keahlian untuk menulis atau mempergunakan kata-kata secara indah 
(Keraf, 2015:112).

Padi (2013:33) mengatakan bahwa majas adalah gaya bahasa dalam bentuk tulisan maupun lisan yang dipakai dalam suatu karangan yang bertujuan untuk mewakili perasaan dan pikiran dari pengarang. Gaya bahasa terbagi menjadi beberapa macam yaitu gaya bahasa perbandingan, gaya bahasa sindiran, gaya bahasa penegasan dan gaya bahasa petentangan. Dari beberapa pendapat para ahli di atas, maka dapat peneliti simpulkan bahwa gaya bahasa merupakan pemanfaatan kekayaan bahasa yang membuat sebuah karya sastra semakin hidup dalam menyampaikan pikiran dan perasaanya baik dalam bentuk lisan maupun tulisan. Majas juga merupakan bagian dari gaya bahasa.

Gaya bahasa sampai saat ini sulit dikategorikan secara jelas. Banyak sekali ahli yang menggolongkan gaya bahasa menurut pandangannya masing-masing. Keraf (2015:115) mengatakan bahwa gaya bahasa dapat ditinjau dari bermacam-macam sudut pandang. Oleh sebab itu, sulit diperoleh kata sepakat mengenai suatu pembagian yang bersifat menyeluruh dan dapat diterima oleh semua pihak. Pandangan-pandangan atau pendapat-pendapat tentang gaya bahasa sejauh ini sekurang-kurangnya dapat dibedakan pertama, dilihat dari segi nonbahasa, dan kedua dilihat dari segi bahasanya sendiri. Menurut Waridah (2009:332) secara garis besar, gaya bahasa terdiri atas empat jenis yaitu, (1) gaya bahasa penegasan, (2) gaya bahasa sindiran, (3) gaya bahasa perbandingan, dan (4) gaya bahasa pertentangan.

Metode penelitian adalah suatu kegiatan ilmiah yang terencana, terstruktur, sistematis yang memiliki tujuan praktis dan teoritis. Metode yang digunakan dalam penelitian ini adalah metode deskriptif analisis. Metode deskritif analisis adalah metode yang digunakan dengan cara menganalisis dan menguraikan data untuk menggambarkan keadaan objek yang akan diteliti yang menjadi pusat perhatian (Ratna, 2007:39). Dalam penelitian ini, deskriptif digunakan untuk menganalisis dan mengkaji gaya bahasa yang ada pada setiap peristiwa tutur dalam acara talkshow Indonesia Lawyers Club (ILC) di TV One edisi Januari-Februari 2019 dan data dalam penelitian ini adalah peristiwa tutur dalam acara talkshow Indonesia Lawyers club (ILC) di TV One edisi JanuariFebruari 2019. Teknik pengumpulan data dilakukan dengan menggunakan teknik rekam, simak dan teknik catat.

\section{HASIL DAN PEMBAHASAN}

Penggunaan gaya bahasa yang terdapat dalam acara talkshow Indonesia Lawyers Club edisi 08 Januari 2019 dengan tema "Menguji Netralitas KPU" adalah sebagai berikut.

\section{Gaya Bahasa Penegasan}

Gaya bahasa penegasan adalah kata-kata berkias yang menyatakan penegasan

untuk meningkatkan kesan pengaruhnya terhadap pendengar ataupun pembaca.

Apofasis atau Praterisio

Apofasis atau praterisio adalah gaya bahasa untuk menegaskan sesuatu dengan cara seolaholah menyangkal hal yang ditegaskan (Waridah, 2009:322). Menurut wiyanto (2012:287) apofasis adalah menegaskan sesuatu dengan cara seolah-olah menyangkalnya.

Gaya bahasa Apofasis atau Praterisio yang terdapat dalam acara talkshow Indonesia Lawyers Club edisi 08 Januari 2019 sebagai berikut.

Anda sepertinya menonjolkan sebuah momentum yang bagus untuk kita tangkap, tapi sayang teramat disayang, saya harus mengatakan dengan sejujurnya agak sedih saya mengatakan momentum tersebut tidak termanfaatkan bahasanya memang betul itu tidak dibatalkan.

Berdasarkan kalimat di atas, terdapat gaya bahasa apofasis yang ditandai dengan kalimat yang seolah-olah menyangkal fakta yakni pertama-tama membicarakan momentum yang bagus untuk ditangkap atau dimanfaatkan, namun kemudian menegaskan tapi sayang teramat disayang, saya harus mengatakan dengan sejujurnya agak sedih saya mengatakan momentum tersebut tidak termanfaatkan bahasanya memang betul itu tidak dibatalkan. 
Repetisi

Repetisi adalah gaya bahasa pengulangan kata, frase, atau bagian kalimat yang dianggap penting untuk memberikan penekanan (Waridah, 2009:322).

Gaya bahasa repetisi yang terdapat dalam acara Talkshow Indonesia Lawyers Club edisi 08 Januari 2019 sebagai berikut.

Cukup pangan, cukup papan, cukup sandang, kemudian kalau sakit bisa ke rumah sakit, ada jaminan hari tua, kemudian ada kesejahteraan, ada kebebasan berpendapat, berserikat, berkumpul, ada kedamaian untuk hidup di Indonesia.

Berdasarkan kalimat di atas, terdapat gaya bahasa repetisi dikarenakan adanya pengulangan kata cukup terlihat pada penggalan kalimat berikut "Cukup Pangan, cukup papan, cukup sandang, kemudian kalau sakit ada jaminan hari tua, kemudian ada...."

\section{Gaya Bahasa Sindiran}

Sinisme

Wiyanto (2012:286) mengatakan bahwa gaya bahasa sinisme adalah umpatan yang amat kasar dan tak mengenal peri kemanusiaan. Cynis artinya 'anjing'. Sinisme adalah sindiran yang berbentuk kesangsian cerita mengandung ejekan terhadap keikhlasan dan ketulusan hati (Waridah, 2009:328)

Gaya bahasa sinisme yang terdapat dalam acara talkshow Indonesia Lawyers Club edisi 08 Januari 2019 sebagai berikut.

Tapi, enggak lucu semua usulan itu diawali dengan kata-kata berani nggak? jadi rasanya kalau kita nggak hadirkan berarti kita penakut. tapi kalau setiap tema ditanya berani enggak? ya terpaksa satu yang dipilih tiga lagi jadinya penakut.

Berdasarkan kalimat di atas, terdapat gaya bahasa sinisme karena terdapat kata sindiran yaitu Berani enggak yang mana kalimat tersebut ditunjukan kepada acara ILC untuk berani tidak mereka mengakat semua tema yang di usulkan oleh pemirsa ILC.

KPU tentu saja ingin menempatkan diri sebagai orang yang netral atau lembaga yang netral tapi orang netral itu itu posisi yang paling mengerikan.

Berdasarkan kalimat di atas, terdapat gaya bahasa sinisme karena terdapat kata sindiran yaitu "Tapi orang netral itu itu posisi yang paling mengerikan" yang mana kalimat tersebut ditunjukan kepada KPU untuk berhati-hatilah menjadi orang netral atau orang yang adil.

\section{Gaya Bahasa Pertentangan}

Antitesis

Antitesis adalah gaya bahasa yang mengungkapkan suatu maksud dengan menggunakan kata-kata yang saling berlawanan (Waridah, 2009:329). Menurut Wiyanto (2012:282) Antitesis yaitu mengungkapkan dua hal yang pengertiannya bertentangan, atau pernyataan yang diungkapkan dengan kata-kata yang saling bertentagan.

Gaya bahasa antitesis yang terdapat dalam acara talkshow Indonesia Lawyers Club edisi 08 Januari 2019 sebagai berikut.

Karena ibarat orang yang berdiri di prapatan jalan kalau tidak ditabrak dari kiri, pasti ditabrak dari kanan, tidak ditabrak dari belakang, di tabrak dari depan.

Berdasarkan kalimat di atas, terdapat gaya bahasa antitesis yang ditunjukan dengan adanya kata yang berlawanan yakni kiri dan kanan, belakang dan depan terlihat pada penggalan kalimat berikut "kalau tidak ditabrak dari kiri, pasti ditabrak dari kanan, tidak ditabrak dari belakang, di tabrak dari depan...."

Di dalam menentukan aturan main dalam debat itu ada kemajuan-kemajuan jadi bukan

\section{kemunduran kemunduran.}

Berdasarkan kalimat di atas, terdapat gaya bahasa antitesis yang ditunjukan dengan adanya kata yang berlawanan yakni kemajuan-kemajuan dan kemunduran-kemunduran terlihat pada penggalan kalimat berikut "... dalam debat itu ada kemajuan-kemajuan jadi bukan kemunduran kemunduran" 
Rapat tertutup dan rapat terbuka disaksikan semua media-media penyelenggara debat.

Berdasarkan kalimat di atas, terdapat gaya bahasa antitesis yang ditunjukan dengan adanya kata yang berlawanan yakni tertutup dan terbuka terlihat pada penggalan kalimat berikut "Rapat tertutup dan rapat terbuka disaksikan semua....".

Oksimoron

Oksimoron ialah gaya bahasa yang mengandung pertentangan dengan menggunakan katakata yang berlawanan dalam frasa yang sama (waridah, 2009:329). Oksimoron yaitu menggunakan kata-kata yang berlawanan artinya dalam kalimat yang sama. Dengan cara tersebut biasanya makna yang dikandung lebih keras atau lebih jelas (Wiyanto, 2012:290).

Gaya bahasa oksimoron yang terdapat dalam acara talkshow Indonesia Lawyers Club edisi 08 Januari 2019 sebagai berikut.

Hak untuk memilih dan dipilih dan terbukti dalam proses rapat-rapat itu terjadi perbaikan, perbaikan pertama perbaikan kedua.

Kalimat di atas dikategorikan sebagai gaya bahasa oksimoron karena adanya kata yang berlawanan dalam frase yang sama, kata tersebut ialah memilih dan dipilih terlihat pada penggalan kalimat berikut "Hak untuk memilih dan dipilih dan terbukti dalam proses...."

\section{Gaya Bahasa Perbandingan}

Alegori

Alegori adalah gaya bahasa untuk mengungkapkan suatu hal melalui kiasan atau penggambaran (Waridah, 2009:331). Menurut Tarigan (2009:24) mengatakan bahwa Alegori adalah cerita yang dikishkan dalam lambang-lambang.

Gaya bahasa alegori yang terdapat dalam acara talkshow Indonesia Lawyers Club edisi 08 Januari 2019 sebagai berikut.

Kita ingin ada natural, orang itu dilihat apa adanya, kandidat ini bukan kosmetik gitu ya pikirannya.

Kalimat di atas dikategorikan sebagai gaya bahasa alegori karena adanya pengungkapan suatu hal melalui kiasan, pengiasan tersebut ialah "Kandidat ini bukan kosmetik". Maksud dari "kandidat ini bukan kosmetik" tersebut bukan berarti alat make up yang dipakai untuk berhias mempercantik wajah. Kosmetik tersebut dimaksudkan agar para kandidat tidak berhias, tidak pencitraan dan tidak menutupi semua kebohongan yang ada.

Hiperbola

Hiperbola adalah cara menyatakan sesuatu dengan melebih-lebihkan (Wiyanto, 2012:281).

Gaya bahasa hiperbola yang terdapat dalam acara talkshow Indonesia Lawyers Club edisi 08 Januari 2019 sebagai berikut.

Kalau saya bisa berjalan di atas air pun orang akan mengeritik saya, bahwa saya tidak bisa berenang, kata Margaret thatcher.

Kalimat di atas dikategorikan sebagai gaya bahasa hiperbola karena adanya kata yang melebih-lebihkan, kalimat yang melebih-lebihkan tersebut ialah "Kalau saya bisa berjalan di atas air". Pada dasarnya orang tidak akan bisa berjalan di atas air.

Berdasarkan hasil analisis data, gaya bahasa yang digunakan dalam acara Talkshow Indonesia Lawyers Club di TV One edisi Januari-Februari 2019 dapat dilihat sebagai berikut.

Gaya bahasa penegasan yang terdiri dari sembilan jenis gaya bahasa yaitu, apofasis, repetisi, aliterasi, pleonasme, retoris, klimaks, antiklimaks, koreksio, dan preterio.

Gaya bahasa sindiran terdiri dari dua gaya bahasa yaitu, sarkasme dan sinisme.

Gaya bahasa pertentangan terdiri dari dua gaya bahasa yaitu, antitesis dan oksimoron.

Gaya bahasa perbandingan terdiri dari empat gaya bahasa yaitu, sinestesia, alegori, antonomasia, dan hiperbola.

Dalam acara Talkshow Indonesia Lawyers Club edisi Januari-Februari 2019. gaya bahasa yang paling sering digunakan atau yang paling sering muncul dalam dialog ialah gaya bahasa repetisi yang termasuk dalam gaya bahasa penegasan. Repetisi adalah gaya bahasa yang mengulang kata-kata 
dalam suatu kalimat penegasan untuk menegaskan suatu hal guna meningkatkan pemahaman pendengarnya. Hal ini terlihat dari hasil analisis pada dialog. Dalam dialog tersebut awalnya penjelasan-penjelasan yang disampaikan oleh narasumber dan moderator ialah secara singkat namun terkadang tidak mudah dipahami oleh pihak satu sama lain sehingga narasumber dan moderator harus mengulang kata-kata yang sama dalam satu kalimat hal inilah yang menimbulkan adanya penggunaan gaya bahasa repetisi yang termasuk dalam gaya bahasa penegasan.

Gaya bahasa penegasan tersebut sering digunakan oleh moderator dan narasumber karena gaya bahasa penegasan merupakan gaya bahasa yang menggunakan kata-kata kiasan untuk menyatakan suatu penegasan untuk memperjelas atau menguatkan kesan terhadap pendengarnya, dengan kata lain majas tersebut dapat memperindah susunan kalimat yang disampaikan secara lisan sehingga menimbulkan nuansa tertentu yang dapat membangkitkan imajinasi pendengarnya.

\section{PENUTUP}

Berdasarkan hasil penelitian dari pembahasan analisis gaya bahasa dalam acara Talkshow Indonesia Lawyers Club edisi Januari-Februari 2019, dapat diambil beberapa kesimpulan, yaitu:

Terdapat empat gaya bahasa yang digunakan dalam acara Talkshow Indonesia Lawyers Club edisi Januari-Februari 2019 yaitu :

Gaya bahasa penegasan : apofasis, repetisi, aliterasi, pleonasme, retoris, klimaks, antiklimaks, koreksio, dan preterio.

Gaya bahasa sindiran : Sarkasme dan sinisme.

Gaya bahasa pertentangan : antitesis dan oksimoron

Gaya bahasa perbandingan : sinestesia, alegori, antonomasia, dan hiperbola.

Gaya bahasa yang muncul pada edisi tanggal 8 Januari 2019 dengan tema "Menguji Netralitas KPU" adalah (1) gaya bahasa penegasan yaitu, apofasi, repetisi, aliterasi, pleonasme, retoris, klimaks dan koreksio. (2) gaya bahasa sindiran yaitu, Sinisme. (3) gaya bahasa pertentangan yaitu, antitesis dan oksimoron. (4) gaya bahasa perbandingan yaitu, alegori dan hiperbola.

Gaya bahasa yang muncul pada edisi tanggal 15 Januari 2019 dengan tema "Menjelang Debat Capres 2019 : Penegakan Hukum di Mata 01 dan 02" adalah (1) gaya bahasa penegasan yaitu, apofasi, repetisi, aliterasi, pleonasme, retoris, klimaks, antiklimaks dan preterio. (2) gaya bahasa sindiran yaitu, sarkasme dan sinisme. (3) gaya bahasa pertentangan yaitu, antitesis. (4) gaya bahasa perbandingan yaitu, sinestesia dan antonomasia.

Gaya bahasa yang muncul pada edisi tanggal 05 Februari 2019 dengan tema "Yang Terjerat Undang-undang ITE-Buni Yani, Ahmad Dhani, Siapa Lagi?" adalah (1) gaya bahasa penegasan yaitu, apofasi, repetisi, aliterasi, pleonasme, retoris, klimaks, antiklimaks, koreksio dan preterio. (2) gaya bahasa sindiran yaitu, sarkasme dan sinisme. (3) gaya bahasa pertentangan yaitu, antitesis. (4) gaya bahasa perbandingan yaitu, antonomasia.

Makna yang muncul dari tiga tema dalam acara Talkshow Indonesia Lawyers Club edisi Januari-Februari 2019 yaitu :

Edisi tanggal 8 Januari 2019 dengan tema "Menguji Netralitas KPU" memiliki makna dengan judul tersebut artinya bahwa masyarakat indonesia masih belum bisa percaya seutuhnya kepada $\mathrm{KPU}$, banyak sekali isu-isu yang tersebar di tengah-tengah masyarakat bahwa KPU itu memihak disalah satu pasangan capres dan cawapres.

Edisi tanggal 15 Januari 2019 dengan tema "Menjelang Debat Capres 2019 : Penegakan Hukum di Mata 01 dan 02" memiliki makna bahwa sebelum debat Capres dimulai nampaknya penegakan hukum di negeri ini berat sebelah, penegak hukum seperti polisi, hakim dan jaksa lebih berpihak kepada tim pertahanan yaitu pasangan capres 01 .

Edisi tanggal 05 Februari 2019 dengan tema "“Yang Terjerat Undang-undang ITE-Buni Yani, Ahmad Dhani, Siapa Lagi?" memiliki makna bahwa berhati-hatilah dalam menyampaikan kritikan ataupun masukan disosial media baik itu facebook, twitter, instagram dan lain-lain. karena pada saat 
ini sudah ada hukum yang mengatur pengguna informasi dan transaksi elektronik yaitu undangundang ITE. yang dilakukan menggunakan media elektronik, nama-nama seperti Buni Yani dan Ahmad Dhani salah satu korban yang telah terkena undang-undang tersebut.

Sehubungan dengan penelitian ini, peneliti mengajukan saran-saran sebagai berikut.

Mahasiswa dan dosen, hasil penelitian ini hendaknya dapat menambah ilmu pengetahuan tentang analisis gaya bahasa khususnya gaya bahasa penegasan, gaya bahasa sindiran, gaya bahasa pertentangan dan gaya bahasa perbandingan.

Peneliti lanjut, hasil penelitian ini hendaknya dapat menjadi pedoman dan masukan untuk peneliti yang lebih mendalam tentang analisis gaya bahasa.

Bagi pengajaran bahasa, penelitian ini diharapkan dapat menambah ilmu pengetahuan khususnya tentang Gaya Bahasa.

\section{UCAPAN TERIMAKASIH}

Ucapan terimakasih ditujukan kepada institusi resmi atau perorangan sebagai penyandang dana, atau yang telah memberikan kontribusi lain dalam penelitian. Ucapan terimakasih dilengkapi dengan nomor surat kontrak penelitian.

\section{DAFTAR PUSTAKA}

Keraf, Gorys. 2015.Diksi dan Gaya Bahasa. Jakarta: Gramedia.

Mery, Mariyawati. 2015. Penggunaan Diksi dan Gaya Bahasa Najwa Shihab pada Acara Mata Najwa di Metro TV. Tidak Diterbitkan. Skripsi. Jember. Fakultas Sastra Universitas Jember.

Padi, Editorial. 2013. Kumpulan Super Lengkap Sastra Indonesia: Puisi, Peribahasa, Pantun, Majas Profil Sastrawan. Jakarta: CV. IImu Padi Infra Pustaka Makmur

Risalah. 2014. Analisis Gaya Bahasa dalam Syair-syair Lagu Noah Album Seperti Seharusnya.

Sugiyono. 2016. Metode Penelitian: Pendekatan Kuantitatif, Kualitatif dan R\&D. Bandung: Alfabeta.

Tarigan, Hendry Guntur. 2009. Pengajaran Gaya Bahasa. Bandung: Angkasa.

Waridah, Ernawati. 2012. Ejaan yang Disempurnakan dan Seputar Kebahasa- Indonesiaan. Bandung : Ruang Kata.

Wiyanto, Asul. 2012. Kitab Bahasa Indonesia: Untuk SD, SMP, SMA, Mahasiswa,Umum. Yogjakarta: Jogja Bangkit Publisher. 